\title{
Novel insights into the combined effect of triorganotin compounds and all-trans retinoic acid on expression of selected proteins associated with tumor progression in breast cancer cell line MDA-MB-231: Proteomic approach
}

\author{
Dana Strouhalova $^{1}$, Lucia Toporova ${ }^{2}$, Marketa Lastovickova ${ }^{1}$, Dana Macejova ${ }^{2}$, Janette \\ Bobalova $^{1}$ and Julius Brtko ${ }^{2}$ \\ ${ }^{1}$ Institute of Analytical Chemistry, Czech Academy of Sciences, v.v.i., Brno, Czech Republic \\ ${ }^{2}$ Institute of Experimental Endocrinology, BMC, Slovak Academy of Sciences, Bratislava, Slovakia
}

\begin{abstract}
Trialkyltins and triaryltins function as nuclear retinoid X receptors (RXR) agonists due to their affinity to the ligand-binding domain of RXR subtypes and function as transcriptional activators. We present the data on combined effects of all-trans retinoic acid (ATRA), retinoic acid receptor (RAR) ligand and tributyltin chloride or triphenyltin chloride (RXR ligands) on protein pattern in MDA-MB-231 cells. Proteomic strategies based on bottom-up method were applied in this study. The total cell proteins were extracted, separated on 2D SDS-PAGE and their characterization was achieved by MALDI-TOF/TOF MS/MS. By employing PDQuest ${ }^{\text {tw }}$ software, we identified more than 30 proteins differently affected by the above compounds. For further studies, we selected specific proteins associated either with metabolic pathway (glyceraldehyde-3-phosphate dehydrogenase) or to cellular processes as apoptosis, regulation of gene transcription or epithelial-mesenchymal transition (annexin 5, nucleoside diphosphate kinase B and vimentin). We have found that treatment of MDA-MB-231 cells with triorganotins reduced the expression of studied proteins. Moreover, the treatment of MDAMB-231 cells with triorganotin compounds together with ATRA resulted in an additional reduction of annexin 5, vimentin and nucleoside diphosphate kinase B. These results demonstrate that RXR/RAR heterodimer may act under this experimental design as permissive heterodimer allowing activation of RXR by triorganotins.
\end{abstract}

Key words: Breast cancer - Triorganotin compounds - Retinoids - Proteomics

\begin{abstract}
Abbreviations: ANXA5, annexin A5; ATRA, all-trans retinoic acid; EMT, epithelial mesenchymal transition; G3P, glyceraldehyde-3-phosphate dehydrogenase; MDA-MB-231, breast cancer cell line, NDKB, nucleoside diphosphate kinase B; 9cRA, 9-cis retinoic acid; RAR, nuclear retinoic acid receptor; $\mathrm{RXR}$, nuclear retinoid $\mathrm{X}$ receptor; TBT-Cl, tributyltin chloride; TPT-Cl, triphenyltin chloride; VIME, vimentin.
\end{abstract}

\footnotetext{
Electronic supplementary material. The online version of this article (doi: 10.4149/gpb_2018042) contains supplementary material, which is available to authorized users.

Correspondence to: Janette Bobalova, Institute of Analytical Chemistry of the CAS, v. v. i. Veveři 97, 60200 Brno, Czech Republic

E-mail: bobalova@iach.cz
}

\section{Introduction}

Nuclear retinoic acid receptors (RARs) and nuclear retinoid X receptors (RXRs) are retinoid/rexinoid inducible transcription factors that play an irreplaceable role in many tissues of higher vertebrates. The retinoid receptors are considered to be ligand-activated, DNA-binding, trans-acting, 
transcription-modulating proteins (Lotan 1995; Sun and Lotan 2002; Brtko and Dvorak 2011, 2015). In addition, their presence in the organism together with their cognate biologically active ligands is essential for many important functions, e.g. cell growth and differentiation, they play an important role in embryonic development, reproduction and apoptosis. Dysfunction of nuclear receptor signaling leads to cell proliferation defects, reproductive and metabolic diseases such as infertility, obesity and diabetes.

Both, retinoids and rexinoids are either natural or synthetic compounds related to retinoic acids (RAs) that act through interaction with two basic types of nuclear receptors belonging to the nuclear receptor superfamily: retinoic acid receptors (RAR $\alpha, R A R \beta$ and $R A R \gamma$ ) and retinoid $X$ receptors (RXRa, RXR $\beta$ and RXR $\gamma$ ) (Germain et al. 2006; Perez et al. 2012). Retinoids are known to inhibit carcinogenesis, suppress tumor growth, and induce tumor cell differentiation and invasion in a variety of tissues. A number of retinoids and rexinoids acting through their cognate nuclear receptors have been tested both, in vitro and in vivo, using cell cultures or animal models (Chen et al. 1995; Macejova at al. 2009; Flodrova et al. 2015). They are considered to be promising anti-cancer drugs for a variety of cancers (Lin el al. 1999; Garattini et al. 2007) but on the other hand, they are teratogenic (Hinds et al. 1997). It has been described that retinoids are able to inhibit mammary gland cancer at animal and human breast cancer (Macejova el al. 2001). The inhibition of breast cancer cell proliferation by retinoids is accomplished by blocking cell cycle progression in the G1 phase. All-trans retinoic acid (ATRA) has been shown to slow the progression of human mammary carcinoma cells (MCF-7) in vitro (Danforth 2004).

Triorganotin compounds contain a group of organometallic moieties characterized by a $\mathrm{Sn}$ atom covalently bound to one or more organic substituents, while some of them represent pollutants of organic origin, e.g. biocides and fungicides exploitable predominantly in agriculture or disinfecting preparations exploitable for adjustment of cooling liquids in industry (Baldi and Mantovani 2008). Stability studies of tributyltin and triphenyltin compounds in water model reported high stability for both tested derivatives (Novotny et al. 2018). A notable breakthrough in this field came out with the important findings that a group of triorganotin compounds possesses capability to disrupt endocrine system (le Maire et al. 2009). Several of them have been gaining a growing importance in oncology (Alama et al. 2009), since they might affect a variety of nuclear receptor signaling pathways through their effect on RXR subtypes. They are agonists of RXR subtypes acting in nanomolar concentrations (Nakanishi 2008). Early studies based on investigations of the selected triorganotin derivatives have shown that these compounds may also modulate steroid hormone synthesis, change mRNA concentration and the activity of the steroidogenous enzymes in various cell lines (Nakanishi 2008). Moreover, they significantly suppress growth of breast cancer cells; the effectiveness is higher at the early stages of breast cancer and lower at some aggressive types of tumors (Brtko and Dvorak 2015). The most of triorganotins are DNA-targeted and mitotic, the action mode occurring via gene-mediated pathway, they are efficacious and might be curative against a select number of neoplasias with a tendency to elicit drug resistance (Tabassum and Pettinary 2006). Recent study also shown that tributyltin chloride (TBT-Cl) and triphenyltin chloride (TPT-Cl) have different effect on cell proliferation and expression of levels of apoptotic protein markers levels in human breast cancer MCF-7 cell line (Fickova et al. 2015). In 2009, Osman et al. reported proteomic profiling of mouse thymoma cells treated with tributyltin oxide and found that this compound altered the expression levels of 12 proteins, including prothymosin alpha (Osman et al. 2009). Nevertheless, triorganotin-induced cytotoxicity involves different mechanisms of action depending on the compound, concentration, and incubation time (Ferreira et al. 2013). In SH-SY5Y neuroblastoma cell line, intensive studies confirmed that tributyltin chloride causes apoptosis (Qing et al. 2013) and endoplasmic reticulum stress via $\mathrm{Ca}^{2+}$ depletion (Isomura et al. 2013).

Both oxidative damage and increased concentration of intramolecular calcium ions seem to be major factors contributing to triorganotin-induced apoptosis in many cell lines (Varela-Ramirez et al. 2011). Recently, the differences of the TBT-Cl and TPT-Cl action in both toxicity and selected RAR and RXR subtype mRNA expression patterns in human breast cancer MCF-7 and MDA-MB-231 cell lines, have been shown (Hunakova et al. 2016). Bohacova et al. (2018) assumed that triorganotin derivatives induce cell death effect on L1210 leukemia cells at submicromolar concentrations independently of P-glycoprotein expression. A recent study also examined both agonistic as well as antagonistic effects of selected triorganotin compounds on vitamin $\mathrm{D}_{3}$ receptor and the peroxisome proliferator-activated receptor gamma (Toporova et al. 2018).

The effect of retinoid receptor ligand of natural origin (ATRA) together with synthetic retinoid X ligands was studied. The aim of this study was to investigate the biological effects of selected environmental endocrine disruptors, tributyltin or triphenyltin compounds (RXR ligands), in the absence or presence of all-trans retinoic acid, a natural RAR ligand.

\section{Materials and Methods}

\section{Chemicals and samples}

All-trans retinoic acid (ATRA), tributyltin chloride (TBT$\mathrm{Cl}$ ) and triphenyltin chloride (TPT-Cl), Dulbecco's modi- 
fied Eagle's medium (DMEM), fetal bovine serum (FBS), Radio-Immunoprecipitation Assay (RIPA) buffer and other conventional chemicals were obtained from Sigma (Schnelldorf, Germany). Penicillin/streptomycin, gentamicin and glutamine were from PAA Laboratories $\mathrm{GmbH}$ (Cölbe, Germany). Enzymes were obtained from Roche Diagnostics (Mannheim, Germany). ZipTip C18 pipette tips were purchased from Merck Millipore (Billerica, MA, USA) and alpha-cyano-4-hydroxycinnamic acid was purchased from LaserBio Labs (Sophia-Antipolis Cedex, France).

\section{Cell culture}

The estrogen receptor negative breast carcinoma cell line MDA-MB-231 was obtained from the HPACC (Health Protection Agency Culture Collections, Salisbury, U.K.), grown and passaged routinely as monolayer cultures in $75 \mathrm{~cm}^{2}$ flasks (Sarstedt, Germany). The cells were used at passages 10-30. Cells were seeded in Petri dishes (Sarstedt, Germany) in Dulbecco's modified Eagle's medium (DMEM) supplemented with $10 \%$ fetal bovine serum (FBS), glutamine and antibiotics (penicillin/streptomycin, gentamicin) and cultured at $37^{\circ} \mathrm{C}$ in humidified atmosphere of $5 \% \mathrm{CO}_{2}$. The cells were treated for $48 \mathrm{~h}$ either with $1 \mu \mathrm{mol} / \mathrm{l}$ ATRA, $100 \mathrm{nmol} / \mathrm{l}$ TBT-Cl or TPT-Cl individually, or with their combination with ATRA. Compounds at selected concentration were dissolved in ethanol and then added into medium. Control cells were incubated with particular concentration of ethanol. After incubation, cells were washed twice with ice-cooled phosphate buffered saline (PBS). The cell lysis was made according to an instruction manual of the RIPA buffer. The cell lysates were stored at $-70^{\circ} \mathrm{C}$ for further analysis. Protein concentrations were assessed using the Lowry assay. Each 2D-PAGE gel was performed from six culture plates.

\section{D-PAGE}

2D-PAGE was performed using ReadyPrep 2D Starter Kit, ReadyStrip IPG strips 7 cm, pH 3-10 nonlinear and 4-20\% Mini-Protean TGX gel (all from Bio-Rad, Hercules, CA, USA). Samples were dialyzed against deionized water using Slide A Lyzer Dialysis Cassettes (Thermo Fisher Scientific, Waltham, MA, USA) with $2 \mathrm{kDa}$ cut-off and lyophilized.

Purified samples were dissolved in $300 \mu$ l of rehydration/ sample buffer and the IPG strip was passively rehydrated using $125 \mu \mathrm{l}$ of reconstituted sample overnight at room temperature. Then, IEF was running with the maximum current of $50 \mu \mathrm{A} /$ strip. After IEF, IPG strips were equilibrated according to the manufacturer's instructions and placed on the top of the Mini-Protean TGX gel. Gel electrophoresis was performed at constant voltage of $160 \mathrm{~V}$. Approximately, $4 \mu \mathrm{g}$ of each samples was loaded on 2D SDS-PAGE. The protein visualization was carried out using Coomassie Brilliant Blue G 250 dye.

\section{In-gel digestion}

Stained protein spots were excised from the gel and digested (after reduction with $10 \mathrm{mmol} / \mathrm{l}$ dithiothreitol and subsequent alkylation with $55 \mathrm{mmol} / \mathrm{l}$ iodoacetamide) with trypsin (digestion buffer: $50 \mathrm{mmol} / 1 \mathrm{NH}_{4} \mathrm{HCO}_{3}, 5 \mathrm{mmol} / \mathrm{l}$ $\mathrm{CaCl}_{2}, 12.5 \mathrm{ng} / \mu \mathrm{l}$ of enzyme) overnight at $37^{\circ} \mathrm{C}$. The resulting tryptic peptides were extracted from the gel by three changes of $0.1 \%$ trifluoroacetic acid (TFA) and acetonitrile solution $(1: 1, v / v)$. Combined extracts were finally dried in the Speed-Vac centrifuge. For mass spectrometric analyses, the samples were purified by ZipTip C18 (Millipore).

\section{Mass spectrometry and database searching}

A solution of $\alpha$-cyano-4-hydroxycinnamic acid (10 mg/ $\mathrm{ml}$ in acetonitrile/0.1\% TFA, $1: 1, \mathrm{v} / \mathrm{v}$ ) for dried-droplet preparation was used for mass spectrometric analysis of peptides. MALDI-TOF MS experiments in positive ion reflectron mode were performed on AB SCIEX TOF/TOF ${ }^{\mathrm{mm}}$ 5800 System (AB SCIEX, Framingham, MA, USA) equipped with $1 \mathrm{kHz} \mathrm{Nd}$ :YAG laser. Acquired mass spectra were processed using TOF/TOF Series Explorer software and the data were submitted to the Mascot database searching. Protein identifications were assigned using the Swiss-Prot and NCBInr databases with taxonomy restriction to Homo sapiens. Maximum tolerance for peptide masses was $0.5 \mathrm{Da}$ and fragment error was set to $0.2 \mathrm{Da}$. Additional parameters used: enzyme trypsin; allowed missed cleavages: up to one, fixed modification: carbamidomethyl, variable modification: oxidation of methionine; peptide charge: +1 ; monoisotopic masses; instrument MALDI-TOF/TOF.

\section{Statistical analyses}

According to PDQuest analyses, the data were presented as the means \pm SD (standard deviation) from three independent experiments. Statistical analyses were performed with Student's $t$-test.

\section{Results}

\section{Proteomic analysis of differently treated cells}

Both triorganotin chloride derivatives alone or in combination with ATRA, natural nuclear retinoid receptor ligand acting via RARs, were used for proteomic studies. The monitoring of the effects and the changes of protein composition were examined within triple negative human breast cancer cell line MDA-MB-231. Differently treated samples as well as untreated control cell lysates were dialyzed using $2 \mathrm{kDa}$ cutoff cassettes to remove undesirable components from RIPA 


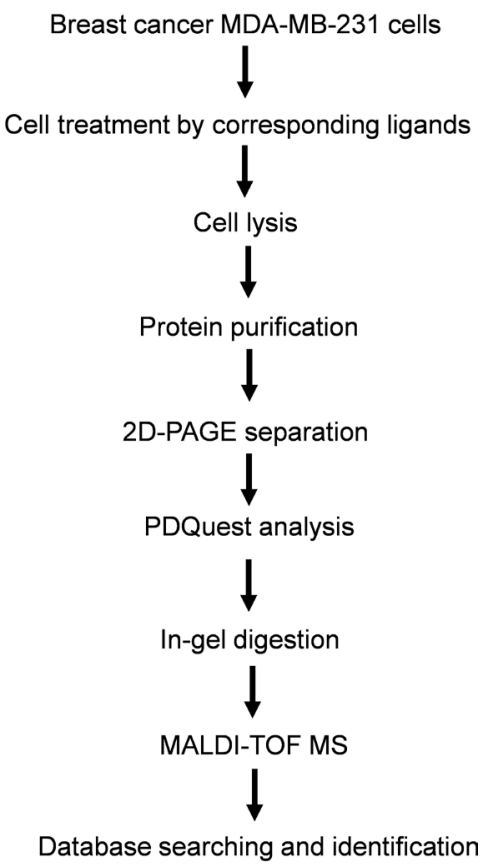

Figure 1. Schedule of methodology approaches.

lysis buffer and cultivation medium. Purified samples were freeze-dried and concentrated protein samples were directly separated by $2 \mathrm{D}$ gel electrophoresis. Obtained 2D maps of individual proteins were processed by PDQuest software and compared with focus on quantitative and qualitative changes. In comparison with the PDQuest 2-D software quantification, the spots, which showed more than a 50\% changes in intensity, were defined and used for tryptic digest, MALDI MS/MS analysis and identification. The schedule of methodology approaches is described in Fig. 1.

Approximately 30 proteins affected by TBT-Cl or TPT-Cl were analyzed (Fig. 2). The information about these specific proteins with their biological role in relationship to breast cancer incidence was summarized in the Table 1.

Obtained 2D qualitative profiles of individual treated samples correspond to our previous results where the effect of natural retinoids, namely ATRA, 9cRA and their combination was monitored (Flodrova et al. 2017). Similarly, there are considerable changes in quantitative representation of several proteins. Protein maps confirm the existence almost of the same types of genes or groups of genes as found within our previous study on natural ATRA treatment effect (Supplementary Material, Fig. S1).

Monitoring of quantitative changes in selected tumor associated proteins

Accordingly, based on our previous work (Flodrova et al. 2017), we focused on specific proteins associated with tumor process, namely annexin A5 (ANXA5), vimentin (VIME), glyceraldehyde-3-phosphate dehydrogenase (G3P) and nucleoside diphosphate kinase B (NDKB) (Fig. 3). Acquired results from $P D Q u e s t$ software analysis confirm the decreas-

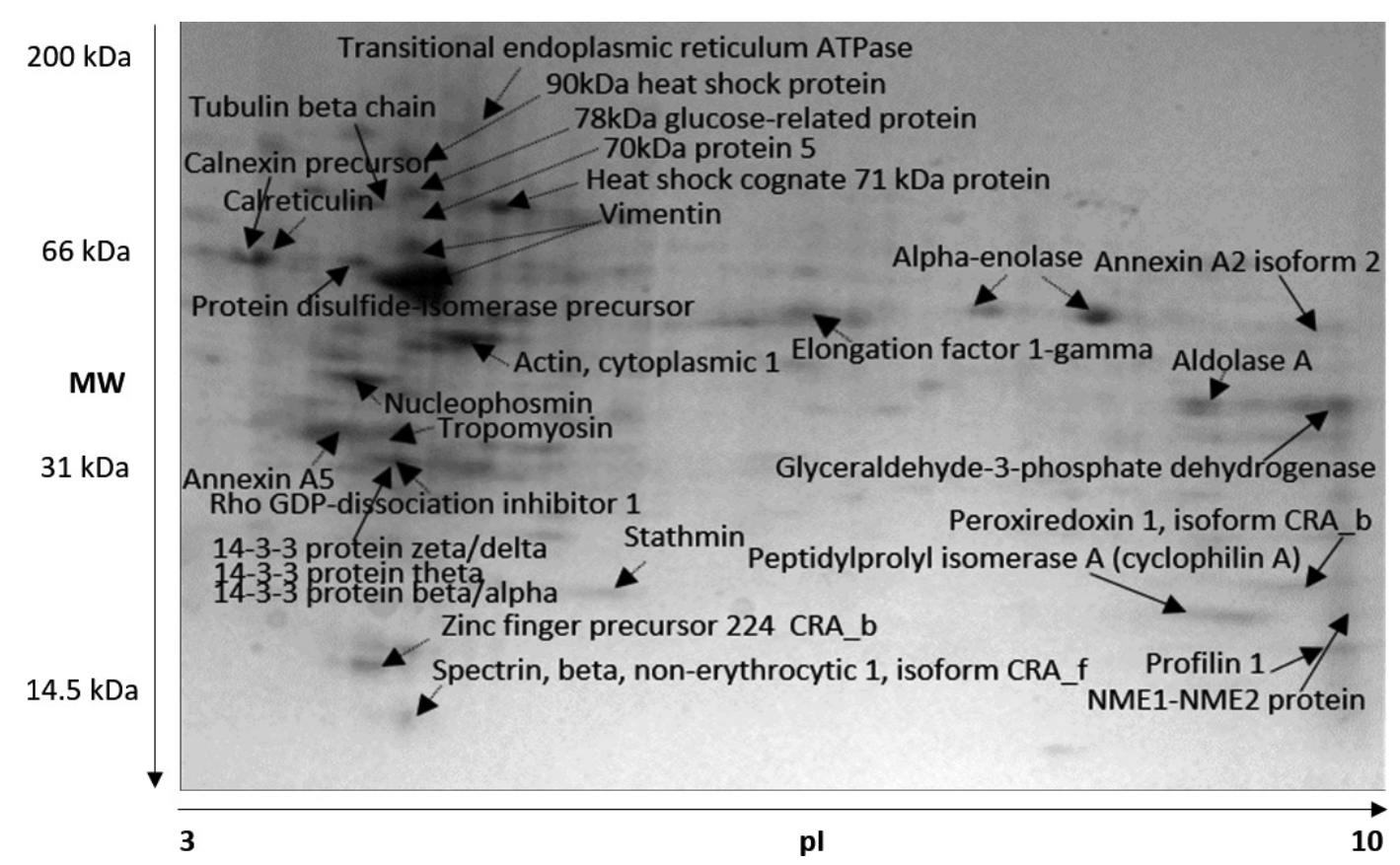

Figure 2.2D gel map showing the summary of identified proteins found in sample of MDA-MB-231 cells treated with TPT-Cl for 48 hours. 
Table 1. Summary of proteins according to specific biological cell function and relationship to breast tumour

\begin{tabular}{|c|c|c|c|c|c|c|c|c|c|c|c|c|}
\hline Protein & Swissprot & 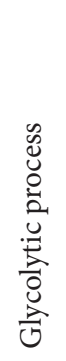 & 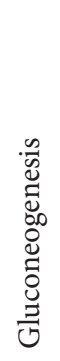 & 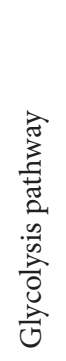 & 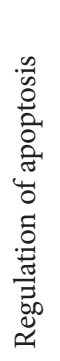 & 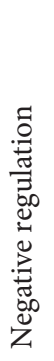 & 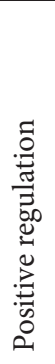 & 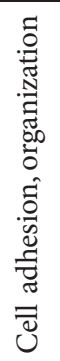 & $\sum_{\text {II }}^{\ominus}$ & 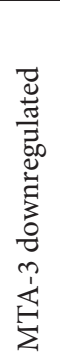 & 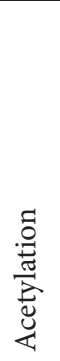 & 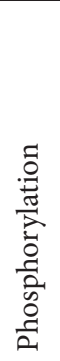 \\
\hline Alpha-enolase & ENOA & & & & & & & & & & & \\
\hline Fructose-bisphosphate aldolase A & ALDOA & & & & & & & & & & & \\
\hline Glyceraldehyde-3-phosphate dehydrogenase & GAPDH & & & & & & & & & & & \\
\hline L-lactate dehydrogenase A & LDHA & & & & & & & & & & & \\
\hline Phosphoglycerate kinase 1 & PGK1 & & & & & & & & & & & \\
\hline Protein disulfide-isomerase A3 & PDIA3 & & & & & & & & & & & \\
\hline Triosephosphate isomerase & TPIS & & & & & & & & & & & \\
\hline 90kDa heat shock protein & HS90B & & & & & & & & & & & \\
\hline 14-3-3 protein epsilon & $1433 \mathrm{E}$ & & & & & & & & & & & \\
\hline $14-3-3$ protein theta & $1433 \mathrm{~T}$ & & & & & & & & & & & \\
\hline 14-3-3 protein zeta/delta & $1433 Z$ & & & & & & & & & & & \\
\hline $60 \mathrm{kDa}$ heat shock protein, mitochondrial & $\mathrm{CH} 60$ & & & & & & & & & & & \\
\hline $78 \mathrm{kDa}$ glucose-regulated protein & GRP78 & & & & & & & & & & & \\
\hline Annexin A5 & ANXA5 & & & & & & & & & & & \\
\hline Calreticulin & CALR & & & & & & & & & & & \\
\hline Cofilin-1 & COF1 & & & & & & & & & & & \\
\hline Eukaryotic translation initiation factor $5 \mathrm{~A}-1$ & EEIF5A & & & & & & & & & & & \\
\hline Glutathione S-transferase P & GSTP1 & & & & & & & & & & & \\
\hline Nucleoside diphosphate kinase A & NDKA & & & & & & & & & & & \\
\hline Nucleoside diphosphate kinase B & NDKB & & & & & & & & & & & \\
\hline Peroxiredoxin-2 & PRDX2 & & & & & & & & & & & \\
\hline Proteasome subunit beta type-1 & PSB1 & & & & & & & & & & & \\
\hline Rho GDP-dissociation inhibitor 1 & GDIR1 & & & & & & & & & & & \\
\hline Serum albumin & ALBU & & & & & & & & & & & \\
\hline Ubiquitin-40S ribosomal protein S27a & RS27A & & & & & & & & & & & \\
\hline Elongation factor 1-gamma & EF1G & & & & & & & & & & & \\
\hline Heat shock $70 \mathrm{kDa}$ protein & HSP72 & & & & & & & & & & & \\
\hline Macrophage-capping protein & CAPG & & & & & & & & & & & \\
\hline Peroxiredoxin-1 & PRDX1 & & & & & & & & & & & \\
\hline Profilin-1 & PROF1 & & & & & & & & & & & \\
\hline Protein S100-A11 & P31949 & & & & & & & & & & & \\
\hline Pyruvate kinase PKM & KPYM & & & & & & & & & & & \\
\hline Tubulin alpha-1A & TBA1A & & & & & & & & & & & \\
\hline Vimentin & VIME & & & & & & & & & & & \\
\hline
\end{tabular}

(Labeled proteins were studied in detail)

ing tendency in expression of selected proteins (Fig. 4A). Expression profiles of studied proteins showed significant change after individual treatment.

Both types of chloride derivatives (TBT-Cl, TPT-Cl) caused the down-regulation of protein expression, and the silencing effect was significantly enhanced by combination with ATRA. Significant effect was evident especially in the case of VIME and NDKB, where the protein levels were reduced up to $10 \%$ (VIME) or were almost completely suppressed (NDKB) (Fig. 4B). This is in agreement with 


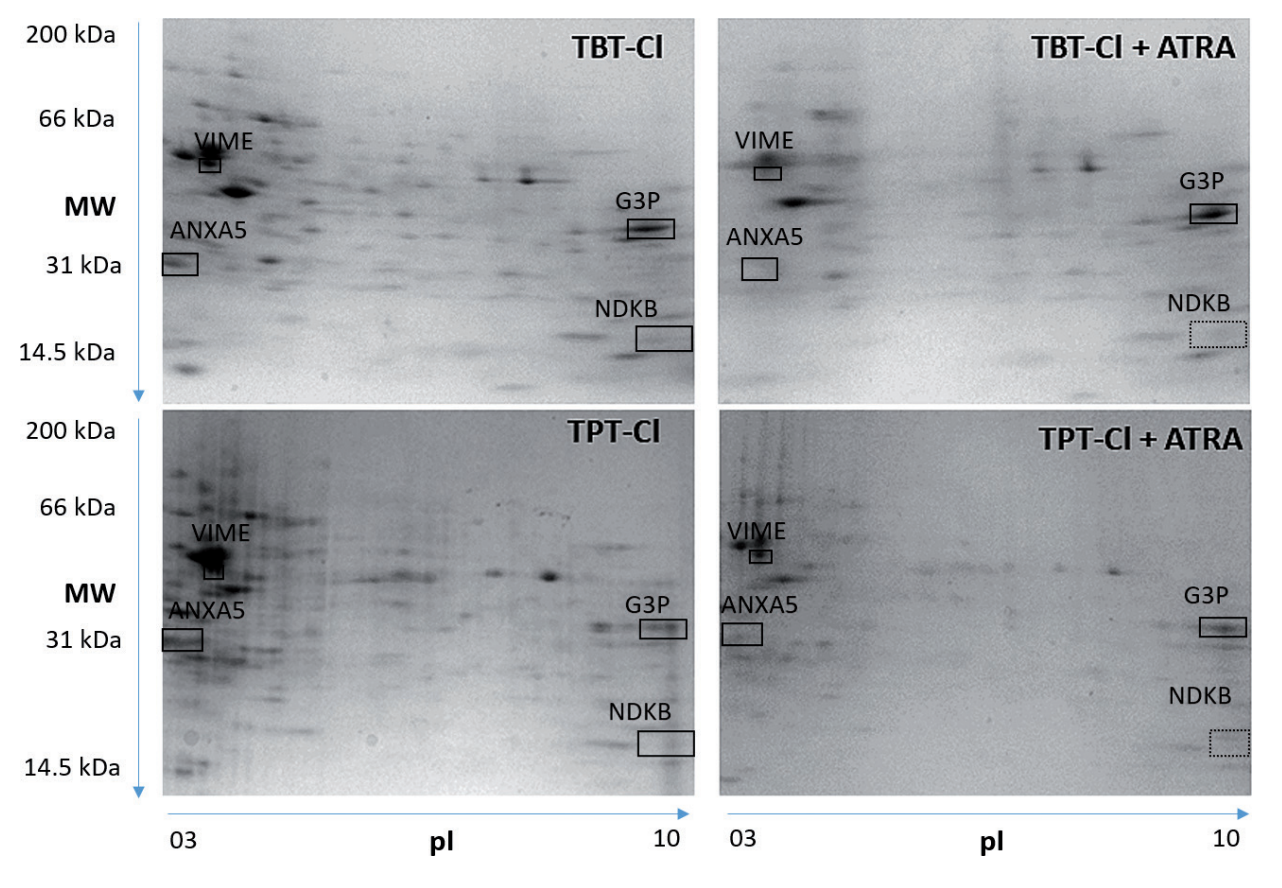

Figure 3. Overview of 2D maps of protein separation after treatments with individual triorganotin chloride compounds. Selected proteins are marked in rectangle marks. ANXA5, annexin A5; ATRA, all-trans retinoic acid; G3P, glyceraldehyde3-phosphate dehydrogenase; NDKB, nucleoside diphosphate kinase $\mathrm{B}$; TBT-Cl, tributyltin chloride; TPT-Cl, triphenyltin chloride; VIME, vimentin. our previous results reporting the same impact of ATRA (RAR agonist) and 9-cis retinoic acid (9cRA) (RXR agonist) (Flodrova et al. 2017).

ANXA5 showed also decreased tendency after triorganotin chlorides (TBT-Cl, TPT-Cl) treatment, as well as the enhanced effect with ATRA combination. On the other hand, in our previous study (Flodrova et al. 2017); there was no evidence of an increased effect of ATRA and 9cRA. Moreover, after treatment by this natural retinoid mixture, the suppression of ANXA5 was insignificant. In the case of G3P, the reduction of protein expression was caused by triorganotin chloride derivatives alone as well as by combination with ATRA in the similar rate.

\section{Discussion}

Our work was focused on the monitoring of biological effects of triorganotin compounds, synthetic ligands of nuclear retinoid $\mathrm{X}$ receptors, in relation to protein profile in triple negative MDA-MB-231 cells. Used endocrine disrupting chemicals TBT-Cl and TPT-Cl upon binding to the ligand binding domain of RXR subtypes are known to act as nuclear RXR agonists, and thus they play a role as transcriptional activators of several biological processes (Toporova et al. 2016). Our research was based on hypothesis that triorganotin compounds, as RXR agonists, might synergistically enhance antitumor effect of natural RARs ligand (ATRA). Thus, the aim of current study was profiling of the proteins upon following treatment: triorganotin chlorides as RXR agonists, ATRA as a RAR agonist, or their combination.

In our previous study, the combined treatments of MDAMB-231 with ATRA and 9cRA, natural ligand of RXRs, were applied to investigate their possible synergistic action. Several proteins, potentially affected by both RXR/RAR ligands, were clearly demonstrated (Flodrova et al. 2017). Accordingly, we have selected proteins that were found to be markedly influenced by treatment with ATRA, triorganotins and their combination and have been associated with cell proliferation, tumor progression and invasiveness, or with cancer suppression. Based on their role in cells, we sorted these proteins according to their three crucial biological processes: epithelium-mesenchymal transition (EMT) process, regulation of apoptosis and glycolysis. Referring to our previous data (Flodrova et al. 2017), selected proteins in this study confirmed the decreasing tendency of expression at protein level. Based on their function within cell, their relation to cancer, and the fact, that their expression or overexpression indicate a poor prognosis, we focused our attention on VIME, NDKB, ANXA5 and G3P, all mentioned as breast cancer markers with either pro-oncogene or metastasis suppressor function.

\section{Epithelium-mesenchymal transition (EMT)}

VIME plays a very important role in the process of metastasis and its expression is typical for neoplastic cells with metastatic properties. The observed protein is a key element regulating the expression of the EMT-related 
A

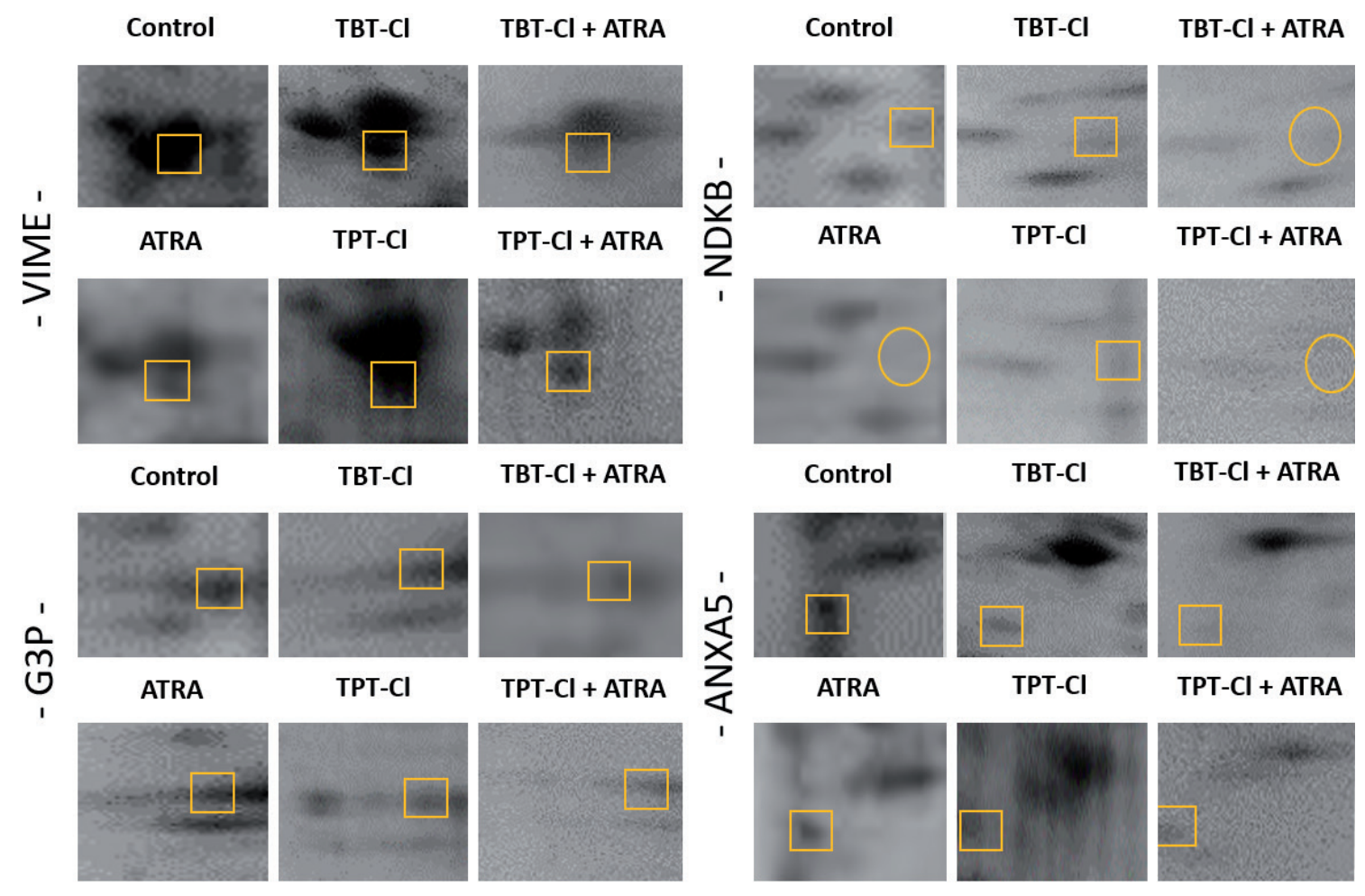

B
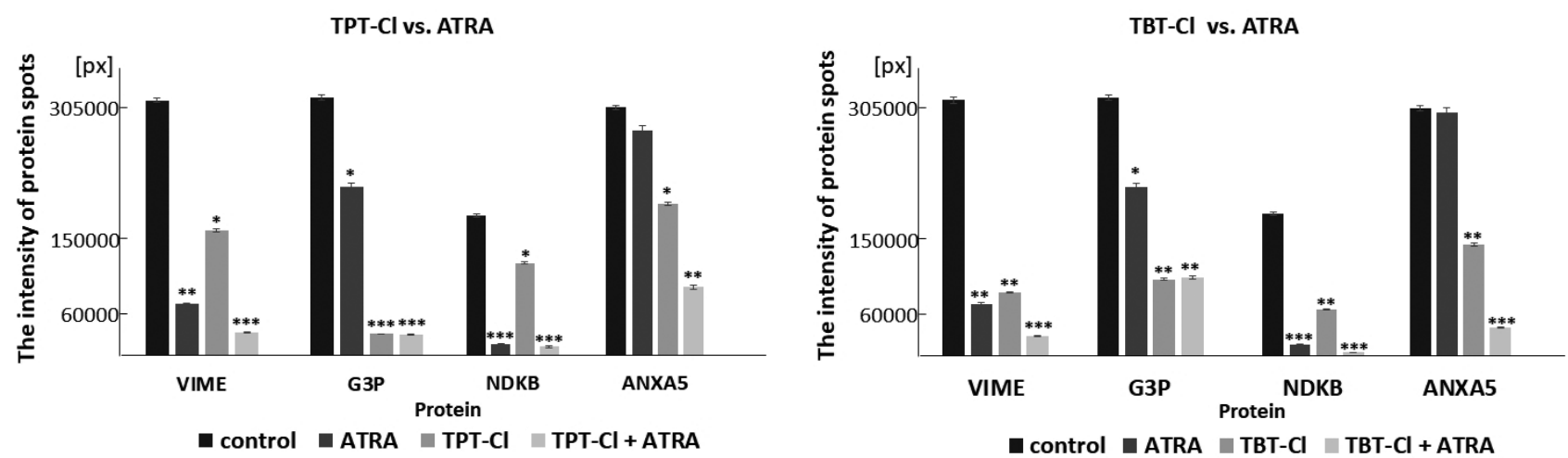

Figure 4. A. Expression profiles of selected proteins after individual treatment. The images represent VIME, G3P, NDKB and ANXA5 protein levels after treatment with tributyltin and triphenyltin chlorides or by their combination with ATRA, vs ATRA or mock treated samples. B. PDQuest analyses results of 2D separation based on automated spot matching algorithm and normalization between gel maps. Quantitative and/ or qualitative representation of chosen proteins after individual synthetic chloride derivatives triphenyltin chloride (TPT-Cl; left) and tributyltin chloride (TBT-Cl; right) compared to their combination with ATRA or to ATRA alone or with mock treated samples. Each bar represented means \pm SD of three separate experiments. ${ }^{\star} p<0.05,{ }^{\star *} p<0.01$ and ${ }^{\star * *} p<0.001$ compared to control group. For abbreviations, see Fig. 3.

transcription factors and thus it is associated with the metastatic spread of cancer. In addition, overexpression of VIME indicates the aggressive and invasive type of breast cancer (Hemalatha et al. 2013; Bottoni et al. 2016) and correlates with upregulated migration and invasion of cancer cells (Calaf et al. 2014). Currently, VIME is supposed to be a potential therapeutic target for cancer research and mainly for understanding - how variable expression of VIME can influence the reversible EMT-MET process. Since, the vimentin represents one of the main factors linked with a poor prognosis in triple negative breast cancer, our findings on the combined effect of ATRA and 
triorganotins resulting in marked decrease of vimentin protein level might be a relevant information for both experimental and clinician oncologists.

\section{Apoptosis regulation}

Next identified protein, strongly linked with an aggressive type of breast cancer is protein NDKB. Nucleoside diphosphate kinase exists in several enzymatically active isoforms and it is known that regulates angiogenesis (Youn et al. 2008). Currently, NDKB is supposed to report the distinct function for extracellular and intracellular type of protein. Considering the variable cell location and given functions, $\mathrm{NDKB}$ can operate as a pro-oncogene and metastasis suppressor, equally (Mandili et al. 2011). The extracellular $\mathrm{NDKB}$ is assumed to be crucial element in signaling of vascular endothelial cell growth factor (VEGF), whereby is able to affect an EMT process (Yokdang et al. 2015; Thiery et al. 2009) as well as progress of metastasis (Serrano-Gomez et al. 2016). Our data clearly demonstrate the combined effect of ATRA and TBT-Cl on NDKB marked decrease at protein level, as well.

ANXA5 is the protein playing an anti-apoptotic role, promoting metastatic process and progression of breast cancer (Wehder et al. 2009; Deng et al. 2013; Peng et al. 2014). Our findings on the reduction of ANXA5 expression by treatment with triorganotin chloride compounds and ATRA, as negative apoptotic regulators, might be also valuable information.

\section{Glycolysis regulation}

G3P represents the key protein of glycolytic and gluconeogenesis processes. G3P upregulation is accompanied with the upregulations of the other genes from glycolytic pathway connected with poor prognosis in cancer cells. This G3P associated upregulation is a crucial regulation factor for study of cancer cell functions and can be useful as a marker of tumor progression (Elkhalfi et al. 2012; Wang et al. 2013; Pucci-Minafra et al. 2017). Moreover, together with other genes (cathepsin D, heat shock protein $27 \mathrm{kDa}$, fructose-bisphosphate aldolase A, alpha-tubulin etc.), G3P protein participates in pathway of MTA-3 downregulation in estrogen negative breast tumors. MTA-3, representing one of the metastasis-associated genes, is a crucial component of an estrogen-dependent pathway affecting the cell growth and differentiation. Specifically, the lack of both, estrogen receptor as well as MTA-3, results in activation of the Snail expression (transcriptional repressor) and EMT process, respectively. MTA-3 is supposed to be a linker between estrogen receptor absence and invasiveness of breast cancer cells (Kumar 2003; Saha Roy and Vadlamudi 2012). Based on the mentioned facts, observed downregulation of G3P protein by ATRA or triorganotins provides the tool for the proteomic research approaches with possible therapeutic application. On the other hand, we did not find the effect of ATRA and triorganotin on G3P expression at protein level.

All mentioned proteins were strongly affected by triorganotin chlorides treatment (downregulated or completely reduced). Generally, observed enhancement of protein suppression, due to combined treatment, confirmed the synergism of both nuclear retinoid receptor ligands. Moreover, since overexpression of all these proteins has been found in the human triple negative breast cancer cells, triorganotininduced silencing of these proteins indicates the promising perspective for further research.

\section{Conclusion}

Based on the fact, that triorganotin compounds are ligands for nuclear retinoid X receptors and ATRA is a natural ligand for nuclear retinoid receptors, we applied the combination of both nuclear receptors cognate ligands in order to investigate their potential combined effect. Our results have clearly shown that chlorides of triorganotin compounds affected more than 30 proteins and that the changes observed for these proteins were highly reproducible. The combined effect of ATRA and triorganotin chlorides predominantly on VIME, NDKB and ANXA5 downregulation suggests that RXR/RAR heterodimer may act under this experimental design as a permissive heterodimer allowing activation of RXR by triorganotins.

In conclusion, our data on combined effect of ATRA and triorganotin chlorides based on proteomic analysis provide new insights into a role of RXR/RAR heterodimer that behaves in the case of VIME and NDKB and partly ANXA5 as a classical permissive heterodimer. On the other hand, the effect of combination ATRA and triorganotin on G3P expression at protein level was not confirmed.

The knowledge achieved from current studies offers further opportunity to study triorganotins more intensively in order to enhance antitumor effect of natural or synthetic RARs ligands and takes advantage of the fact on direct activation of RXR by triorganotins. The activation of ligand inducible transcription factors - nuclear receptors, which forms conditional types of RXR-RAR heterodimers, is extremely complex because activation of RXRs by either natural ligands (9-cis retinoic acid) or synthetic ligands (triorganotins) may yield in induction of different regulatory pathways. The further intensive research work on this topic is warranted.

Acknowledgement. This work was supported by institutional support RVO:68081715 of the Institute of Analytical Chemistry of the CAS, v. v. i., SAV-18-16, APVV-15-0372, APVV-0160-11 and VEGA 2/0171/17 grants. 
Conflict of interest. The authors declare that there are no conflicting financial interests.

\section{References}

Alama A, Tasso B, Novelli F, Sparatore F (2009): Organometallic compounds in oncology: implications of novel organotins as antitumor agents. Drug Discovery Today 14, 500-508 https://doi.org/10.1016/j.drudis.2009.02.002

Baldi F, Mantovani A (2008): A new database for food safety: EDID (Endocrine disrupting chemicals - Diet Interaction Database). Ann. Ist. Super. Sanità 44, 57-63

Bohacova V, Seres M, Pavlikova L, Kontar S, Cagala M, Bobal P, Otevrel J, Brtko J, Sulova Z, Breier A (2018): Triorganotin derivatives induce cell death effects on L1210 leukemia cells at submicromolar concentrations independently of P-glycoprotein expression. Molecules 23, 1053 https://doi.org/10.3390/molecules23051053

Bottoni P, Isgro MA, Scatena R (2016): The epithelial-mesenchymal transition in cancer: a potential critical topic for translational proteomic research. Exp. Rev. Prot. 13, 115-133 https://doi.org/10.1586/14789450.2016.1112742

Brtko J, Dvorak Z (2011): Role of retinoids, rexinoids and thyroid hormone in the expression of cytochrome p450 enzymes. Curr. Drug Metab. 12, 71-88 https://doi.org/10.2174/138920011795016881

Brtko J, Dvorak Z (2015): Triorganotin compounds - ligands for „rexinoid“ inducible transcription factors: Biological effects. Toxicol. Lett. 234, 50-58 https://doi.org/10.1016/j.toxlet.2015.02.009

Calaf GM, Balajee AS, Montalvo-Villagra MT, Leon M, Navarrete D, Alvarez RG, Roy D, Narayan G, Abarca-Quinones J (2014): Vimentin and Notch as biomarkers for breast cancer progression. Oncol. Lett. 7, 721-727 https://doi.org/10.3892/ol.2014.1781

Chen S, Ostrowski J, Whiting G, Roalsvig T, Hammer L, Currier SJ, Honeyman J, Kwasniewski B, Yu K-L, Sterzycki R, et al. (1995): Retinoic acid receptor gamma mediates topical retinoid efficacy and irritation in animal models. J. Invest. Dermatol. 104, 779-783 https://doi.org/10.1111/1523-1747.ep12606988

Danforth DN (2004): All trans-retinoic acid acts synergistically with hydroxytamoxifen and transforming-growth factor beta to stimulate apoptosis in MCF-7 breast cancer cells. J. Endocrinol. 183, 395-404 https://doi.org/10.1677/joe.1.05497

Deng SS, Wang JG, Hou LM, Li JS, Chen G, Jing BQ, Zhang XM, Yang ZW (2013): Annexin A1, A2, A4 and A5 play important roles in breast cancer, pancreatic cancer and laryngeal carcinoma, alone and/or synergistically. Oncol. Lett. 5, 107-112 https://doi.org/10.3892/ol.2012.959

Elkhalfi B, Senhaji N, Benomar H, Soukri A (2012): Study of glyceraldehyde-3-phosphate dehydrogenase expression in the tumor process of: Breast, cervix and prostate cancers. Adv. Biol. Chem. 2, 335-340 https://doi.org/10.4236/abc.2012.24041

Ferreira M, Blanco L, Garrido A, Vieites JM, Cabado AG (2013): In vitro approaches to evaluate toxicity induced by organotin compounds tributyltin (TBT), dibutyltin (DBT), and monobutyltin (MBT) in neuroblastoma cells. J. Agric. Food Chem. 61, 4195-4203 https://doi.org/10.1021/jf3050186

Fickova M, Macho L, Brtko J (2015): A comparison of the effects of tributyltin chloride and triphenyltin chloride on cell proliferation, proapoptotic p53, Bax, and antiapoptotic Bcl-2 protein levels in human breast cancer MCF-7 cell line. Toxicol. in Vitro 29, 727-731 https://doi.org/10.1016/j.tiv.2015.02.007

Flodrova D, Benkovska D, Macejova D, Bialesova L, Hunakova L, Brtko J, Bobalova J (2015): Proteomic analysis of changes in the protein composition of MCF-7 human breast cancer cells induced by all-trans retinoic acid, 9-cis retinoic acid, and their combination. Toxicol. Lett. 232, 226-232 https://doi.org/10.1016/j.toxlet.2014.09.030

Flodrova D, Toporova L, Lastovickova M, Macejova D, Hunakova L, Brtko J, Bobalova J (2017): Consequences of the natural retinoid/retinoid $\mathrm{X}$ receptor ligands action in human breast cancer MDA-MB-231 cell line: Focus on functional proteomics. Toxicol. Lett. 281, 26-34 https://doi.org/10.1016/j.toxlet.2017.09.001

Garattini E, Gianni M, Terao M (2007): Retinoids as differentiating agents in oncology: A network of interactions with intracellular pathways as the basis for rational therapeutic combinations. Curr. Pharm. Des. 13, 1375-1400 https://doi.org/10.2174/138161207780618786

Germain P, Staels B, Dacquet C, Spedding M, Laudet V (2006): Overview of nomenclature of nuclear receptors. Pharmacol. Rev. 58, 685-704 https://doi.org/10.1124/pr.58.4.2

Hemalatha A, Suresh TN, Kumar MLH (2013): Expression of vimentin in breast carcinoma, its correlation with Ki67 and other histopathological parameters. Indian J. Cancer 50, 189-194 https://doi.org/10.4103/0019-509X.118724

Hinds TS, West WL, Knight EM (1997): Carotenoids and retinoids: A review of research, clinical, and public health applications. J. Clin. Pharmacol. 37, 551-558 https://doi.org/10.1002/j.1552-4604.1997.tb04336.x

Hunakova L, Macejova D, Toporova L, Brtko J (2016): Anticancer effects of tributyltin chloride and triphenyltin chloride in human breast cancer cell lines MCF-7 and MDA-MB-231. Tumour Biol. 37, 6701-6708 https://doi.org/10.1007/s13277-015-4524-6

Isomura M, Kotake Y, Masuda K, Miyara M, Okuda K, Samizo S, Sanoh S, Hosoi T, Ozawa K, Ohta S (2013): Tributyltin-induced endoplasmic reticulum stress and its $\mathrm{Ca} 2+$ mediated mechanism. Toxicol. Appl. Pharmacol. 272, 137-146 https://doi.org/10.1016/j.taap.2013.05.026

Kumar R (2003): Another tie that binds the MTA family to breast cancer. Cell 113, 142-143 https://doi.org/10.1016/S0092-8674(03)00274-5

le Maire A, Grimaldi M, Roecklin D, Dagnino S, Vivat-Hannah V, Balaguer P, Bourguet W (2009): Activation of RXR-PPAR heterodimers by organotin environmental endocrine disruptors. EMBO Rep. 10, 367-373 https://doi.org/10.1038/embor.2009.8 
Lotan R (1995): Retinoids and apoptosis: Implications for cancer chemoprevention and therapy. J. Natl. Cancer Inst. 87, 1655-1657 https://doi.org/10.1093/jnci/87.22.1655

Lin RJ, Egan DA, Evans RM (1999): Molecular genetics of acute promyelocytic leukemia. Trends Genet. 15, 179-184 https://doi.org/10.1016/S0168-9525(99)01710-2

Macejova D, Dvorcakova M, Weiss R, Scheiblhofer S, Mostbock S, Liska J, Szabova L, Zorad S, Thalhamer J, Brtko J (2001): Reduction of 1-methyl-1-nitrosourea-induced mammary gland carcinoma by in vivo application of immunostimulatory CpG motifs in Sprague-Dawley rats. Gen. Physiol. Biophys. 20, 445-448

Macejova D, Krizanova O, Brtko J (2009): Different mRNA expression profiling of nuclear retinoid, thyroid, estrogen and PPARgamma receptors, their coregulators and selected genes in rat liver and spleen in response to short term in vivo administration of 13-cis retinoic acid. Toxicol. Lett. 184, 114-120 https://doi.org/10.1016/j.toxlet.2008.10.031

Mandili G, Marini C, Carta F, Zanini C, Prato M, Khadjavi A, Turrini F, Giribaldi G (2011): Identification of phosphoproteins as possible differentiation markers in all-trans-retinoic acidtreated neuroblastoma cells. PLoS One 6, e18254 https://doi.org/10.1371/journal.pone.0018254

Nakanishi TJ (2008): Endocrine disruption induced by organotin compounds; organotins function as a powerful agonist for nuclear receptors rather than an aromatase inhibitor. Toxicol. Sci. 33, 269-276 https://doi.org/10.2131/jts.33.269

Novotny L, Sharaf L, Abdel-Hamid ME, Brtko J (2018): Stability studies of endocrine disrupting tributyltin and triphenyltin compounds in an artificial sea water model. Gen. Physiol. Biophys. 37, 93-99 https://doi.org/10.4149/gpb_2017051

Osman AM, van Kol S, Peijenburg A, Blokland M, Pennings JLA, Kleijans JCS, van Loveren H (2009): Proteomic analysis of mouse thymoma EL4 cells treated with bis(tri n-butyltin)oxide (TBTO). J. Immunotoxicol. 6, 174-183 https://doi.org/10.1080/15476910903051723

Peng BY, Guo CM, Guan HW, Liu SQ, Sun MZ (2014): Annexin A5 as a potential marker in tumors. Clin. Chim. Acta 427, $42-48$ https://doi.org/10.1016/j.cca.2013.09.048

Perez E, Bourguet W, Gronemeyer H, de Lera AR (2012): Modulation of RXR function through ligand design. Biochim. Biophys. Acta 1821, 57-69 https://doi.org/10.1016/j.bbalip.2011.04.003

Pucci-Minafra I, Di Cara G, Musso R, Cancemi P, Albanese NN, Roz E, Minafra S (2017): Retrospective proteomic screening of 100 breast cancer tissues. Proteomes 5, 15 https://doi.org/10.3390/proteomes5030015

Qing Y, Liang YF, Du QQ, Fan P, Xu HG, Xu YP, Shi N (2013): Apoptosis induced by Trimethyltin chloride in human neuroblastoma cells SY5Y is regulated by a balance and cross-talk between NF-kappa B and MAPKs signaling pathways. Arch. Toxicol. 87, 1273-1285 https://doi.org/10.1007/s00204-013-1021-9
Saha Roy S, Vadlamudi RK (2012): Role of estrogen receptor signaling in breast cancer metastasis. Int. J. Breast Cancer 2012, 654698 https://doi.org/10.1155/2012/654698

Serrano-Gomez SJ, Maziveyi M, Alahari SK (2016): Regulation of epithelial-mesenchymal transition through epigenetic and post-translational modifications. Mol. Cancer 15, 18 https://doi.org/10.1186/s12943-016-0502-x

Sun S. Y, Lotan R (2002): Retinoids and their receptors in cancer development and chemoprevention. Crit. Rev. Oncol. Hematol. 41, 41-55 https://doi.org/10.1016/S1040-8428(01)00144-5

Tabassum S, Pettinary CJ (2006): Chemical and biotechnological developments in organotin cancer chemotherapy. Organomet. Chem. 691, 1761-1766 https://doi.org/10.1016/j.jorganchem.2005.12.033

Thiery JP, Acloque H, Huang RY, Nieto MA (2009): Epithelialmesenchymal transitions in development and disease. Cell 139, 871-890 https://doi.org/10.1016/j.cell.2009.11.007

Toporova L, Macejova D, Brtko J (2016): Radioligand binding assay for accurate determination of nuclear retinoid $\mathrm{X}$ receptors: A case of triorganotin endocrine disrupting ligands. Toxicol. Lett. 254, 32-36 https://doi.org/10.1016/j.toxlet.2016.05.005

Toporova L, Illes P, Dvorak Z, Bobal P, Otevrel J, Brtko J (2018): Effects of selected triorganotin compounds on transcriptional activity of vitamin D3 receptor and peroxisome proliferatoractivated receptor gamma. Gen. Physiol. Biophys. 37, 589-596 https://doi.org/10.4149/gpb_2018021

Varela-Ramirez A, Costanzo M, Carrasco YP, Pannell KH, Aguilera RJ (2011): Cytotoxic effects of two organotin compounds and their mode of inflicting cell death on four mammalian cancer cells. Cell Biol. Toxicol. 27, 159-168 https://doi.org/10.1007/s10565-010-9178-y

Wang DR, Moothart DR, Lowy DR, Qian XL (2013): The expression of glyceraldehyde-3-phosphate dehydrogenase associated cell cycle (GACC) genes correlates with cancer stage and poor survival in patients with solid tumors. PLoS One 8, e61262 https://doi.org/10.1371/journal.pone.0061262

Wehder L, Arndt S, Murzik U, Bosserhoff AK, Kob R, von Eggeling F, Melle C (2009): Annexin A5 is involved in migration and invasion of oral carcinoma. Cell Cycle 8, 1552-1558 https://doi.org/10.4161/cc.8.10.8404

Yokdang N, Nordmeier S, Speirs K, Burkin HR, Buxton ILO (2015): Blockade of extracellular NM23 or its endothelial target slows breast cancer growth and metastasis. Integr. Cancer Sci. Ther. 2, 192-200 https://doi.org/10.15761/ICST.1000139

Youn B, Kim HD, Kim J (2008): Nm23-H1/nucleoside diphosphate kinase as a key molecule in breast tumor angiogenesis. Expert Opin. Ther. Targets 12, 1419-1430

https://doi.org/10.1517/14728222.12.11.1419

Received: September 27, 2018

Final version accepted: October 26, 2018

First published online: February 26, 2019 